\title{
Effects of van Hiele's phase-based teaching strategy and gender on pre-service mathematics teachers' attitude towards geometry in Niger State, Nigeria
}

\author{
H. Usman' ${ }^{1}$, W. T. Yew ${ }^{2}$, and S. Saleh ${ }^{3}$
}

\section{Abstract}

The study investigated the effects of van Hiele's phase-based teaching strategy and gender on pre-service mathematics teacher attitude towards geometry in Niger state, Nigeria. The study employed pre-test and post-test quasi-experimental design using a two-by-two (2x2) factorial matrix with one experimental and control group. The experimental group was exposed to Van Hiele's phase-based teaching strategy while the control group was taught same topics with conventional teaching strategy. Three null hypotheses with corresponding research question were formulated to guide the study. Attitudes Towards Geometry questionnaire (ATGQ) was the instrument employed to collect data from 149 sampled pre-service mathematics teachers from the two college of education situated in Niger State, Nigeria. The sample colleges were selected using purposive sampling technique. A reliability coefficient of 0.73 was obtained for Attitudes Towards Geometry questionnaire. Two-way Analysis of Variance (ANOVA) was employed in analysing the data at 0.05 level of significance. The results of the study revealed that van Hiele's phase-based teaching strategy is more effective in improving pre-service mathematics teachers' attitude towards geometry. It was recommended among others, that since van Hiele phase-based teaching strategy was found to be effective in enhancing pre-service mathematics teacher attitude towards geometry, the strategy should be employed by lecturers in course of teaching students. The teacher education programme should be geared towards training of mathematics lecturers to learn van Hiele phase-based teaching strategy as it supports effective teaching and learning which there by improving learners' attitudes towards learning geometry.

Keywords: $\quad$ attitude towards geometry, gender, pre-service mathematics teachers, van Hiele phase-based teaching

\section{Introduction}

Attitudes in teaching and learning process are well-established structures of positive or negative assessment, enthusiastic emotion and dispositions to social objects (Knezek \& Christensen, 2018). It can be explained as stable conduct or rather manner of reacting, as portrayal of feeling or opinion. It could also be ascribed to a specific tendency to perform or respond in a positive or negative direction with a view towards specific circumstances and ideas (Issa, Bashorun, Mubashir, \& Adewusi, 2010). Bowen and Richman (2000) conceived attitude as a combination of personal choice about a particular element. Researcher such as Pavlovicova and Zahorska (2015) opined that positive attitude to geometry leads learner to success in mathematics. They maintained

\footnotetext{
${ }^{1}$ Hassan Usman lectures at College of Education, Minna, Nigeria and currently a researching at the School of Educational studies Universiti Sains Malaysia. Email: babanibro73@gmail.com

${ }^{2 \& 3}$ Wun Thiam Yew, and Salmiza Saleh are all in the School of Educational studies Universiti Sains Malaysia.
} 
Effects of van Hiele's phase-based teaching strategy and gender on pre-service mathematics teachers' attitude towards geometry in Niger State, Nigeria

H. Usman, W. T. Yew, and S. Saleh

that effort to enhance attitude towards mathematics at basic level offers foundation for advanced studies in mathematics, and similarly impacted positively on mathematics achievement at a particular school level.

Researchers such as Di Martino and Zan (2015) and Hannula (2002) observed that attitude is a confusing concept which is frequently used without appropriate definition. Di Martino and Zan (2015) and Krippendorff, (2018) asserted that attitude lies within the intellectual crossroad of many different domains. Yet in spite of difficulties observed, there have been numerous attempts at defining and redefining attitude in the context of mathematics education (Aiken, 1970; Allport, 1935; Di Martino \& Zan, 2001).

Originally, Allport's (1935) definition of attitude focuses on the effects of an individual's mental state on their behaviours within a particular situation. In confirmation of this, Awofala (2013) stressed that there have been many other definitions which focus on the nature of attitude as evidenced by behaviour. Talton and Simpson (1986) and Awofala (2013) see attitude "as the positive or negative degree of affect associated with a certain subject or learned predispositions to respond negatively or positively to certain objects, situations, concepts or persons" (p. 2). In a multidimensional meaning of attitude, actions seem not to appear clearly (Daskalogianni \& Simpson, 2000), accordingly, attitude towards mathematics is thus perceived to be a collection of beliefs and feelings associated with mathematics (Zan \& Di Martino, 2007). In general, Awofala (2013) stress that "attitude recognizes three main components in an attempt to define it thus: emotional response, beliefs regarding the subject, and behaviour related to the subject" (p. 2). At this point, Hart (1989) and Breda, Pino-Fan, and Font (2017) asserted that an individual's attitude towards mathematics is explained in a more complex way by the feelings that he/she associates with mathematics which have a positive or negative assessment on person's beliefs towards mathematics, and by extension how he/she acts.

In Nigeria, therefore, it is obvious that in spite of the central position accorded to mathematics in the National Policy on Education (FGN, 2004), the students' poor outlook towards the subject (geometry aspect of mathematics) is a confirmation that something is wrong with mathematics teaching in Nigeria (Awofala \& Nneji, 2012). Having noticed this, Ale (1989) and Surya and Syahputra (2017) identified five main challenges associated with school mathematics in developing nations and Nigeria in particular to include: Curricula problems; Teacher problems; Pupil problems; Language Problems; and infrastructural problems. Larsen (2013), Prendergast and O'Donoghue (2014) in their separate observations identified learning environment, teacher quality and meaningful teaching methods among several factors that play a vital role in the formation and development of a student's attitude.

Consequently, from the listed challenges identified, Ale (1989), Gorozidis and Papaioannou (2014) and Steiner and Mendelovitch (2017) maintained that teacher factor in the area of teaching ineffectiveness appears more prevalent and hence constitutes the main barrier to learners' advancement of positive attitudes in the direction of mathematics. Thus, finding out the most appropriate model so as to develop student attitude towards geometry led the determination to make use of van Hiele's geometric model.

The model explains process of reasoning particularly in geometry, it comprises of five levels and five phases of instruction already applied in several research (Abdullahi \& Zakaria, 2013; Abu et al., 2012; Alex and Mammen 2016; Atebe, 2008; Cannizaro \& Menghhni, 2006; Chang et al., 
2007; Chew, 2007; Chew, \& Lim, 2013; Erdogan \& Durmus, 2009; Fuys et al., 1988; Hoffer, 1983; \& Usiskin, 1982) associated to teaching and learning of geometry. In all of these researches, it was found out to be efficient in improving learners' performance. The model/theory was initiated and developed by two Dutch mathematicians in the 1950s, Pierre van Hiele and his wife Dina van Hiele-Geldof. According to Van Hiele (1986) the five levels according are: Recognition, Analysis, Order, Deduction and Rigor. The levels are arrived at as a result of experience and instruction rather than age. Hence, a learner is expected to have adequate knowledge of (classroom or otherwise) geometric thoughts to move to a sophisticated stage of difficulty. In order word, the characteristics of the model is hierarchical in nature. Respectively, the levels (levels 1-5) go together with by five phased-based teaching strategies. Chew (2009) and Choi-Koh (2000) established this by indicating that students has to pass over all the five phases to attain every of van Hiele's level. Accordingly, each and every level of geometric thought is arrived at as a result of sequence of the phases. The five phases of instruction are: Information, Guided orientation, Explicitation, Free-orientation and Integration. Consequently, when teacher in particular, tries to shift up level of geometry thought through strategically planed instruction process that is in accordance with phase-base instruction, it will assist the learner to develop positive attitude toward geometry.

In view of the above, teaching approaches have a significant impact on learners' attitudes towards mathematics (Ifamuyiwa, \& Akinsola, 2008; Savelsbergh, Prins, Rietbergen at al. 2016; Sonnert, Sadler, Sadler, \& Bressoud, 2015). Hence the need to investigate as to whether teaching strategy will have effect on the attitude of pre-service mathematics teachers' attitude towards geometry

\section{Theoretical Background}

The connection between attitude and achievement was found in the theory of reason which according to Karen and Rimer (2015), rest on basic belief that the greatest indicator of a behavior is intention, which is decided by the attitude towards social normative perception regarding the behavior. This means that immediately a group of people are positively inclined to a behaviour, they are likely to take up the conduct. This was therefore confirmed by Nwagbo (2006) that the enhancement of the proper mentality to learning by learners is central to the realisation of excellent achievement in that learning.

Information on whether attitude of student towards mathematics and geometry improve students' academic achievement is much less clear on the basis of the controversial findings from the literature. Nicolaidou and Philippou (2003) observed that a learner developed positive attitude towards mathematics during first time in school, yet, as they advance their attitudes assume less positive and oftentimes become negative at high school. Negative attitudes are the outcome of regular and recurrent challenges when addressing mathematical tasks and these might become somewhat steady if measures are not taken (Petty, 2018). There are collection of circumstances explaining reason why learners' attitude to geometry as a branch of mathematics turn out to be negative with the school grade. The reasons include; the tension to perform excellently, over demanding tasks, uninteresting lessons and less positive attitudes on the part of teachers (Nicolaidou \& Philippou, 2003).

Several researches such as Obi, Agwagah and Agah (2014), Ajai and Imoko (2015) and Hassan (2015) have examined the effects of carefully planned instructional strategies on learners' academic attainment in mathematics in Nigeria, none of this study examined the efficacy of such strategies on learners' attitudes towards mathematics. In confirmation of this, Awofala Arigbabu, 
Effects of van Hiele's phase-based teaching strategy and gender on pre-service mathematics teachers' attitude towards geometry in Niger State, Nigeria

H. Usman, W. T. Yew, and S. Saleh

and Awofala, (2013) said that one reasonable clarification for the above statement is that evaluation approaches of learners' learning mathematics are repeatedly tailored towards the direction of the attainment of cognitive skills with slight or no inclination for affective skills, this verifies that, attitude as a key concept in the affective domain is not often evaluated in college mathematics examination; somewhat, evaluation of learners' attitudes to mathematics is carried out in cautiously organized research with the expectation of offering solutions to learners' uninspiring and poor achievement in mathematics. Consequently, scholars such as Turner, Johnston, Kebritchi, Evans and Heflich (2018) are engaged in discovering new strategies that can be employed to improve learners' attainment in the cognitive domain. In general, instructional strategies in mathematics education are examined with the hope of refining learners' learning outcomes (Sun \& Anderman 2018)

According to Nkwe (1985), attitude is repeatedly considered in educational research. This is because positive attitude is associated with academic achievement. In confirmation of this, Ma and Kishor (1997) stressed that there is a universal belief that learners particularly pupils, absorb more efficiently when they are attracted by what they study and that they will accomplish better in mathematics if they like mathematics. Likewise, Bindak (2004) observed in particular reference to geometry that, if students have positive attitude towards geometry they are expected to like geometry, partake in the classroom activities and to be high achievers in geometry.

In a study carried out by Awofala, Arigbabu, and Awofala (2013) to find out the impact of framing and team assisted individualized instructional strategies, employing $3 \times 2 \times 2$ factorial matrix, with a population of 350 senior secondary SSII students in Nigeria (172 males and 178 females) revealed a significant main effect of treatment and gender on attitude means score of subjects exposed to the TAI strategy. The finding also shows a significant attitude towards mathematics based on gender favouring male gender. There was however no substantial main effect of attitudes toward mathematics on style of categorization among the students. Similarly, substantial two ways interaction effects of treatment and style of categorization and gender on students' attitudes toward mathematics was noticed. Furthermore, no significant interaction effects of treatment and gender on students' attitudes toward mathematics. On the other hand, significant difference existed on the three-way interaction effect of treatment, gender, and style of categorization on students' attitudes toward mathematics. In conclusion, TAI and framing strategies were more effective in promoting students' attitudes toward mathematics. Hence, it was suggested that teaching method can positively change students' attitudes toward mathematics.

Karjanto (2017) studies the attitude towards mathematics between the students registered in the Foundation Year Programme at Nazarbayev University. The research was carried out quantitatively, an instrument developed by Tapia and Marsh II was adopted for data collection. The inventory comprises of 40 items on the five-point Likert scale. The result indicates a positive correlation between earlier high achievement in mathematics and favorable attitude towards it. There was no significant difference based on gender of students in terms of their attitude towards mathematics

The work of Slavik (2015) aimed at finding out the impact of a spreadsheet-based learning environment on leaners' attitudes toward mathematics in which the sample consisted of learners registered in an undergraduate mathematics with applications course at a small private liberal arts university in Northeast Ohio. 3 instruments namely: Attitudes Toward Mathematics Inventory, Master, Student, Partner, Extension-of-Self Framework and the Master, Student, Partner, 
Extension-of-Self Framework were used for data collection. At the commencement and conclusion of the study to measure the initial 36 participants' attitudes toward mathematics, ATMI was used, MSPE was used to measure a minor sample of six students' means of relating with technology; and finally the SOLO was used to measure the understandings and intelligence of mathematical concepts for the same six students. The finding shows that there was no significant difference in students' attitudes based on the quantitative findings; qualitative results however, suggest that students' value of mathematics increased. In addition, for most students, the use of spreadsheet technology to interact with mathematics increased over the duration of the study.

In a study by Sunzuma, Masocha, and Zezekwa (2013) on secondary school students' attitudes toward learning of geometry in which stratified random sampling was employed with a sample drawn from 100 'O' level students of three urban high schools. Questionnaire which comprises of 15 closed questions was the instrument adapted and modified from Fennema-Shermann Mathematics Scale (1977) was used for data collection. Positive learners' attitudes toward the utility of geometry were established from the finding. In addition, majority of the learner alleged that geometry is cherished and very essential in assisting them in their future careers. The result similarly revealed that the bulk of the learners in Bindura urban did not like answering geometrical problems and that geometry is very hard to both male and female learners, as such therefore, the attitudes of learners can be influenced by teaching strategy employed by the teacher. The work of Thompson (1993) shows that the tutors' geometry teaching strategy and his character significantly influenced learners' positive attitude to geometry as such, without individual determination in learning geometry by the learner, it will be extremely difficult for the learner to perform well in the geometry and mathematics in general. Accordingly, Betiku (2001), stressed that teachers' content knowledge significantly influenced learners' academic achievement. In supporting this, Mayberry (1983) indicated that in mathematics classes, high quality teaching strategy is one of the highest impacts on the learners' attainment of geometry knowledge which is lacking among preservice and in-service middle school instructors.

Mogari (1999) investigated four constituents of attitudes in school Geometry. These are, enjoyment, motivation, perception of the significance of geometry and freedom from anxiety of geometry. The finding of the study shows a very weak correlation among performance and the four variables mentioned earlier. To this end and in supporting Mogari (1999) work, Geddes and Fortunato (1993) acknowledged that a lot of learners run into problems and achieved poorly in geometry.

Bhowmik and Banerjee (2016) studied the relationship between achievement and attitude towards mathematics of secondary school students'. The approach used for the study was a descriptive type, involving 394 secondary grade ten students from six diverse high schools. The Mathematics Attitude Scale and Mathematics Achievement Test were the instrument used for data collection. The data was analysed using independent samples t-tests and Pearson's correlation coefficient at 0.05 significant level using SPSS software. The findings revealed that in gender difference there had been significant difference on the students' attitude towards mathematics, though there is no significant difference in achievement in mathematics. Also there is a significant positive correlation between attitude towards mathematics and achievement in mathematics.

Mata, Monteiro, and Peixoto (2012) studied how certain diverse but interconnected variables like background, motivation, and social support might lead to clarification of learner attitudes towards mathematics and understanding of the defining features of these attitudes in the school environment. The sample of the study consisted of one thousand one hundred and nineteen (1719) 
Effects of van Hiele's phase-based teaching strategy and gender on pre-service mathematics teachers' attitude towards geometry in Niger State, Nigeria

H. Usman, W. T. Yew, and S. Saleh

Portuguese students selected from fifth-to-twelfth grade. The study adapted intrinsic motivation inventory as the instrument for data collection. One unit of the questionnaire named, (In my Math Class) measures students' perceptions of teacher and peer support as well as students' attitudes. The findings indicated positive attitudes towards mathematics and also stressed the main effects of grade and mathematics achievement on the attitudes. There was no significant gender difference though the female showed a continuous weakening in attitudes the more they advanced in school. A hierarchical examination by means of structural equation modelling showed that motivationrelated variables are the central predictors of attitudes towards mathematics and that teachers and the social support of peers are also significantly important in understanding these attitudes.

In general, several studies, namely Fraser and Kahle (2007), Ma and Kishor (1997) Matos and De la Torre (2010), and Nicolaidou and Philippou (2003), were carried out to understand the association among learner attitudes towards mathematics and academic achievement. In Ma and Kishor's (1997) work, a weak correlation between these variables was noticed and these relationships were dependent on numerous variables. On the other hand, other studies show a positive correlation between student attitudes towards mathematics and student academic achievement. Alongside is the finding of Nicolaidou and Philippou (2003) which show a significant correlation between attitudes and academic achievement. Students with positive attitudes achieved better. The work of Mato and De La Torre (2010) on secondary school students similarly revealed that those with improved academic achievement had a positive attitude to mathematics than students with weak academic achievement. This finding according to Sanchez et al. (2004) was established in broader study on attitudes among secondary school students in nine countries.

Lipnevich et al. (2011) emphasize the significance of attitudes in predicting academic achievement in a research developed in USA and Russian with middle school students. The finding revealed that mathematics attitudes clarified a variance of $25 \%$ to $32 \%$ in mathematics performance with majority of explained variance independent of ability in mathematics.

Having said that, Georgiou et al. (2007) demonstrated that an excellent performance can be used to predict a positive attitude towards mathematics, correspondingly, positive attitude can not predict better performance. However, these writers highlight the position of a teachers and schools in altering attitudes, affirming that, mathematics performance can be enhanced by, for instance, better teaching strategy, motivation by teachers or improve course books, which has consequences for the improvement of attitudes towards mathematics.

Gender differences on students' attitude and of course achievement was included in this study because gender have continued to be an issue in the Nigeria educational system and indeed the whole of African countries and the world at large (Farajimakin, 2010). Accordingly, Egorova (2016), stressed that despite extensive research on gender differences on attitude and achievement, many controversial issues and contradictions remain. Despite this, gender is one issue that has continued to receive attention in recent times especially in science, technology and mathematics education (Hassan, 2015). The gap on mathematics achievement based on gender distribution according to Cimpian (2016) deserves unique consideration in schools, since that is where potential mathematicians, computer scientists, and other science, technology, engineering, and mathematics (STEM) professionals tend to reside. It is against this background that this study aimed at investigating possible effects of van Hiele's phase-based teaching strategy and gender on pre-service mathematics teachers' attitude towards geometry in Niger state, Nigeria. 


\section{Aim and objectives of the Study}

The aim of this study is to determine the effects of van Hiele's phase-based teaching strategy and gender on pre-service mathematics teachers' attitude towards geometry in Niger state, Nigeria.

Specifically, the research objectives were as follows:

1. Determine the main effect of van Hiele's phase-based teaching strategy on pre-service mathematics teachers' attitude towards Geometry.

2. Determine the main effect of gender on pre-service mathematics teachers' attitude towards geometry.

3. Determine the interaction effect of van Hiele's phase-based teaching strategy and gender on pre-service mathematics teachers' attitude towards geometry.

Based on the objectives, the following null hypotheses were formulated to guide the study:

Ho1 There is no significant main effect of teaching method on pre-service mathematics teachers' attitude towards geometry.

$\mathrm{Ho}_{2}$ There is no significant main effect of gender on pre-service mathematics teachers' attitude towards geometry.

$\mathrm{Ho}_{3}$ There is no significant interaction effect of teaching method and gender on Preservice Mathematics Teachers' attitude towards geometry.

\section{Method}

\section{Research Design}

The study employed pre-test and post-test quasi experimental design using a two-by-two (2x2) factorial matrix with one experimental and control group. This research design signifies two levels of treatment or method of teaching (van Hiele's phase-based teaching strategy and conventional teaching strategy) and two levels of gender (male and female). The research design is shown in Table 1.

Table 1 Research Design

\begin{tabular}{llccc}
\hline Group & Gender & Pretest & Treatment & Posttest \\
\hline Experimental group & Male & $\mathbf{O}_{1}$ & $\mathbf{X}_{\mathbf{1}}$ & $\mathbf{O}_{\mathbf{2}}$ \\
& Female & & $\mathbf{X}_{2}$ & $\mathbf{O}_{2}$ \\
\hline Control group & Male & $\mathbf{O}_{1}$ & & \\
& Female & & & \\
\hline
\end{tabular}

Where,

$\mathbf{O}_{1-}$ pre attitude test scores of experimental \& control groups

$\mathbf{O}_{2}$ - post attitude test scores of experimental \& control groups,

$\mathbf{X}_{1}$ - van Hiele's phase-based teaching strategy

$\mathbf{X}_{2}$ conventional teaching strategy 
Effects of van Hiele's phase-based teaching strategy and gender on pre-service mathematics teachers' attitude towards geometry in Niger State, Nigeria

H. Usman, W. T. Yew, and S. Saleh

\section{Population, Sample and Sampling Technique}

The population for this study is made up of all the 5458 pre-service mathematics teachers in the two colleges of education in Niger state, Nigeria (College Department of Mathematics, 2017). The target population was year one (100 level) pre-service mathematics teachers who had registered MAT 122 (coordinate geometry) during 2017/2018 session.

The sample of this study consisted of 149 pre-service mathematics teachers currently enrolled in MAT 122 from two purposively selected colleges of education in Niger State, Nigeria. The reason for choosing 100 level pre-service mathematics teachers is because MAT 122 which is designed to prepare the pre-service mathematics teachers to teach students based on secondary school content constitutes part of the course to be studied at this level. Two course lecturers taken MAT 122 were purposively selected one each from the selected colleges. The sample size of the preservice mathematics teachers in the experimental and control group are 86 (62 male and 24 female) and 63 (54 male and 9 female) respectively captured from the intact class.

\section{Instrumentation}

Attitude Towards Geometry Questionnaire (ATGQ) is an instrument adapted from Tapia (2004). The instrument is made up of three constructs; self-confidence, value and motivation and 20 items employed to draw responses from pre-service mathematics teachers. It was divided into two sections. Section A was designed to collect demographic information of the respondents while Section B consisted of 20 items on pre-service mathematics teachers' attitude toward geometry. Pre-service mathematics teachers were asked to answer the options that match their view in the following way: Strongly Disagreed (SD), Disagreed (D), Agreed (A), and Strongly Agreed (SA). The items were scored on the basis of the weight of each point. That is, 1, 2, 3, 4 for SD, D, A, SA for the items respectively. The Attitude Towards Geometry Questionnaire was however pretested and post tested to determine the effect of change in attitude of pre-service mathematics teachers after exposure to the van Hiele's phase-based teaching strategy and conventional teaching strategy.

The test instrument was validated by two senior lecturers of mathematics education department one each from sampled colleges and one expert in the field of mathematics education from the university. The items were corrected and modified on the basis of suggestions and recommendations by the experts. The reliability coefficient for the ATGQ was found to be 0.73 which is considered reliable (Pallant, 2010; Wells \& Wollack, 2003).

\section{Procedure for data collection and analysis}

The entire study lasted for 8 weeks. The first week was spent on administering pre-test on ATGQ to the two colleges involved in the study, the College of Education A and College of Education B. This was followed by application of treatment; the van Hiele's phase-based teaching strategy by the assigned mathematics lecturer to the experimental group and conventional teaching strategy to the control group for six weeks. Both groups were taught the same contents. The posttest, was administered at the eight weeks of the experiment.

Descriptive statistics such as mean and standard deviation was used to answer all the research questions. Two ways Analysis of variance (ANOVA) statistics in Statistical Package for Social Sciences (SPSS) version 22.0 was used to test all the hypotheses at 0.05 , alpha level of significance. 


\section{Results}

Results of the two-way Analysis of variance (ANOVA) post-test attitude towards geometry scores are presented in Table 2.

Table 2. Two-way analysis of variance (ANOVA) Result of the attitude posttest Scores of Experimental and the Control Group

\begin{tabular}{|c|c|c|c|c|c|c|}
\hline Source & $\begin{array}{l}\text { Type III Sum } \\
\text { of Squares }\end{array}$ & Df & Mean Square & $\mathrm{F}$ & Sig. & $\begin{array}{c}\text { Partial Eta } \\
\text { Squared }\end{array}$ \\
\hline Corrected Model & $6333.553^{\mathrm{a}}$ & 3 & 2111.184 & 53.797 & .000 & .527 \\
\hline Intercept & 287742.763 & 1 & 287742.763 & 7332.233 & .000 & .981 \\
\hline Treatment & 4218.280 & 1 & 4218.280 & 107.490 & .000 & .426 \\
\hline Gender & 2.523 & 1 & 2.523 & .064 & .800 & .000 \\
\hline Treatment * Gender & 64.077 & 1 & 64.077 & 1.633 & .203 & .011 \\
\hline Error & 5690.313 & 145 & 39.244 & & & \\
\hline Total & 532228.000 & 149 & & & & \\
\hline Corrected Total & 12023.866 & 148 & & & & \\
\hline
\end{tabular}

Table 2 shows the two-way analysis of variance (ANOVA) comparison of attitude post-test scores for the effects of teaching method and gender on pre-service mathematics teachers' attitude towards geometry between the experimental and the control Group. An analysis of the Table indicates significant difference in the attitude scores for the main effect of treatment (i.e., teaching method), $\mathrm{F}(1,145)=107.49, \mathrm{p}<0.05$, partial eta squared $=.43$. The results implied that there is significant main effect of teaching method on pre-service mathematics teachers' post-test scores of attitude towards geometry. On the basis of this, hypothesis $2 \mathrm{a}$ was rejected.

The main effect of gender on pre-service mathematics teachers' attitude towards geometry was found to be not significant given by $\mathrm{F}(1,145)=.06, \mathrm{p}>0.05$, partial eta squared $=.00$. which implied that there is no significant main effect of gender on the post-test attitude scores of preservice mathematics teachers. Thus, hypothesis $2 \mathrm{~b}$ was failed to be rejected.

Likewise, there was no significant interaction effect of treatment and gender on attitude towards geometry of the pre-service mathematics teachers on post-test scores $\mathrm{F}(1,145)=1.63, \mathrm{p}>0.05$ partial eta squared $=.01$. Thus, hypothesis $2 \mathrm{c}$ was failed to be rejected. In other words, the effect of treatment (i.e., teaching method) on attitude towards geometry of the pre-service mathematics teachers on post-test scores does not depend on the gender of the pre-service mathematics teachers. This therefore suggest that, irrespective of gender, learning through Van Hiele's phase-based teaching strategy was significantly more effective in improving the attitude towards geometry of pre-service mathematics teachers in comparison with conventional teaching strategy.

\section{Discussion and conclusion}

The results in Table 2 show the two-way analysis of variance (ANOVA) result of attitude posttest score of experimental and control groups differ significantly. The result indicated that treatment using Van Hiele's phase-based teaching strategy has produced significant difference on pre-service mathematics teachers' attitude towards geometry. Based on the above results, it was inferred that the significant difference observed may be credited to the opinion of Ma and Kishor (1997) who stressed that there is a general acceptance that learners particularly pupils absorb more efficiently when attracted by what they study and as such will accomplish better in mathematics. The result 
is therefore in agreement with the results of Awofala, Arigbabu, and Awofala (2013)) employing pre-test and post-test control group quasi experimental design $(3 \times 2 \times 2$ factorial matrix), with a population of 350 senior secondary SSII students in Nigeria (172 males and 178 females). The analysis of covariate and scheffe test results revealed a substantial main effect of treatment and gender on attitude mean score of subjects exposed to the TAI strategy. This is supported by Sunzuma, Masocha, and Zezekwa (2013), and Mata, Monteiro, and Peixoto (2012) whose study were respectively meant at carrying the effect of the Van Hiele's model on learners' attitude towards mathematics.

The result of this study is also supported by Karjanto (2017) who studies the attitude towards mathematics between the students registered in the Foundation Year Programme at Nazarbayev University. The research was carried out quantitatively, an instrument developed by Tapia and Marsh II was adopted for data collection. The inventory comprises of 40 items on the five-point Likert scale. The result indicates a positive correlation between earlier high achievement in mathematics and favorable attitude towards it. The work of Thompson (1993) had shown that the teachers' geometry instructional strategy and his/her personality greatly influenced students' positive attitude towards geometry as such, this work by Thompson (1993) is in consonance with the current study. Also, in agreement with the current study is the work of Bhowmik and Banerjee (2016) on the relationship between performance and attitude towards mathematics of secondary school students. The approach used for the study was a descriptive type, involving 394 secondary grade 10 students from six diverse high schools. The results revealed that there is a significant positive correlation between attitude towards mathematics and achievement in mathematics.

In line with current study is the research conducted by Mata, Monteiro, and Peixoto (2012) on how diverse but interconnected variables might lead to clarification of attitude of students toward mathematics and understanding of the essential features of these attitudes in the context of school. The sample of the study involved 1719 Portuguese students selected from fifth-to-twelfth grade. The study adapted intrinsic motivation inventory as the instrument for data collection. The finding indicated favourable students' attitudes towards mathematics, in addition the main effects of mathematics achievement on the attitudes and grade was positive. A hierarchical examination indicated that motivational related variables are essential predictors of attitudes to mathematics and significantly important in understanding these attitudes are teacher and the social support from peers.

However, the result of this study is in disagreement with the result of Slavik, (2015) aimed at finding out the impact of a spreadsheet-based learning environment on leaners' attitudes toward mathematics in which the sample consisted of learners registered in an undergraduate mathematics with applications course at a small private liberal arts university in Northeast Ohio. The finding based on quantitative result shows no significant difference in students' attitudes.

In a related study by Sunzuma, Masocha, and Zezekwa (2013) on secondary school students' attitudes towards learning of geometry in which stratified random sampling was employed with a sample drawn from 100 'O' level pupils of three urban high schools is in disagreement with the current study. The result revealed that the bulk of the learners in Bindura urban did not like answering geometrical problems and that geometry is very hard to both male and female learners, as such therefore, the attitudes of learners can be influenced by teaching strategy employed by the teacher. In view of this result therefore Thompson (1993) opined that teachers' personality and geometry instructional strategy significantly influenced learners' positive attitude to geometry as 
such, in the absence of individual attempt in learning geometry by the learner, it will be extremely difficult for the learner to perform well in the geometry and mathematics in general. Mogari's (1999) work on four components of attitudes in Euclidean Geometry is also in contradiction with the current study. His finding on relationship between achievement and each of the four variables shows a very weak relationship. To this end and in supporting Mogari's (1999) work, Geddes and Fortunato (1993) attested that several learners experience difficulties and therefore achieved poorly in geometry.

The result of this study is also in contradiction with the work of Bhowmik and Banerjee (2016) on relationship between achievement in mathematics and attitude towards mathematics of secondary school students. The approach used for the study was a descriptive type, involving 394 secondary grade ten students from six diverse high schools. The results revealed that there is no significant correlation between attitude towards mathematics and achievement in mathematics.

The effect of Van Hiele's phase-based teaching strategy on attitude scores based on gender was determined using post-test mean achievement of males and female taught in experimental and control group. The result in Table 2, which indicated that treatment using Van Hiele's phase- based teaching strategy improved pre-service mathematics attitude mean scores and showed no significant difference on gender. This is an indication that Van Hiele's phase-based teaching strategy minimizes gender differences. This concurs with the results of Karjanto (2017) on attitude towards mathematics between the students registered in the Foundation Year Programme at Nazarbayev University. The study was conducted quantitatively, and an inventory developed by Tapia and Marsh II was the instrument adopted for data collection. The result revealed no significant difference based on gender of students in terms of their attitude towards mathematics. The result of the current study is also in agreement with the result of Mata, Monteiro, and Peixoto (2012) with sample consisted of 1719 Portuguese students selected from fifth-to-twelfth grade. The result revealed that there was no significant gender difference though the female showed a continuous weakening in attitudes the more they advanced in school.

In disagreement with the study is the result of Bhowmik and Banerjee (2016) in which descriptive approach was employed on 394 secondary grade ten students from six diverse high schools. The result revealed that there is significant gender difference on the students' attitude towards mathematics. The study of Awofala, Arigbabu, and Awofala (2013) is also in contradiction with the current study. The study employed a $3 \times 2 \times 2$ factorial matrix, with a sample of 350 senior secondary SSII students in Nigeria. The result also shows that males had significant attitudes toward mathematics than female.

In conclusion, the result obtained from the data gathered for attitude posttest scores for the effects of teaching method and gender on pre-service mathematics teachers' attitude towards geometry indicated significant difference in the attitude scores for the main effect of treatment. The main effect of gender on pre-service mathematics teachers' attitude towards geometry was found to be not significant. Similarly, there was no significant interaction effect of treatment and gender on attitude towards geometry of the pre-service mathematics teachers on posttest scores.

The results of the study indicate that Van Hiele's phase-based teaching strategy is more effective than conventional instructional strategy in improving pre-service teachers' attitude towards geometry. Consequently, the use of Van Hiele's phase based instructional strategy could be regarded as one of the veritable strategies for enhancing attitude of pre-service mathematics teacher in Niger state and Nigeria in general. 
Effects of van Hiele's phase-based teaching strategy and gender on pre-service mathematics teachers' attitude towards geometry in Niger State, Nigeria

H. Usman, W. T. Yew, and S. Saleh

\section{Reference}

Abdullah, A. H., \& Zakaria, E. (2013b). The effects of van Hiele's phase-based instruction using the geometer's sketchpad (GSP) on students' levels of geometric thinking. Research Journal of Applied Sciences, Engineering and Technology, 5(5), 1652-1660.

Abu, M. S., Ali, M. B., \& Hock, T. T. (2012). Assisting primary school children to progress through their van Hiele's levels of geometry thinking using Google SketchUp. ProcediaSocial and Behavioral Sciences, 64, 75-84.

Alex, J. K., \& Mammen, K. J. (2016). Lessons learnt from employing van Hiele theory-based instruction in senior secondary school geometry classrooms. Eurasia Journal of Mathematics, Science \& Technology Education, 12(8), 2223-2236.

Atebe, H. U. (2008). Student's van Hiele levels of geometric thought and conception in plane geometry: a collective case study of Nigeria and South Africa. Unpublished doctoral dissertation, Rhodes University, South Africa

Awofala, A. O., Arigbabu, A. A., \& Awofala, A. A. (2013). Effects of framing and team assisted individualised instructional strategies on senior secondary school students'attitudes toward mathematics. Acta Didactica Napocensia, 6(1), 1.

Betiku, O. F. (2001). Causes of mass failure in Mathematics examinations among students. $A$ Commissioned paper presented At Government Secondary School, Karu, Abuja Science Day, First March.

Bhowmik, M., \& Banerjee (Roy), B. (2016). A study on relationship between achievement in mathematics and attitude towards mathematics of secondary school students'. IRA International Journal of Education and Multidisciplinary Studies (ISSN 2455-2526), 4(3), 402-408. doi:http://dx.doi.org/10.21013/jems.v4.n3.p7

Bindak, R. (2004). Disentangling the nexus: Attitude to mathematics and technology in a computer learning environment. Educational Studies in Mathematics, 36, 275-290.

Breda, A., Pino-Fan, L. R., \& Font, V. (2017). Meta didactic-mathematical knowledge of teachers: criteria for the reflection and assessment on teaching practice. EURASIA Journal of Mathematics, Science and Technology Education, 13(6), 1893-1918.

Cannizzaro, L., \& Menghini, M. (2006). From geometrical figures to definitional Rigour: Teachers' analysis of teaching units mediated through van Hiele's theory. Canadian Journal of Math, Science \& Technology Education, 6(4), 369-386.

Chang, K. E., Sung, Y. T., \& Lin, S. Y. (2007). Developing geometry thinking through multimedia learning activities. Computers in Human Behavior, 23(5), 2212-2229. doi.org/10.1016/j.chb.2006.03.007

Chew C M (2009). Assessing pre-service secondary mathematics teachers' geometric thinking. Proceedings of the 5th Asian Mathematical Conference Penang, Malaysia.

Chew, C. M., \& Lim, C. S. (2013). Enhancing primary pupils' geometric thinking through phasebased instruction using the geometer's sketchpad. The Asia Pacific Journal of Educators and Education (formerly known as Journal of Educators and Education), 28(1), 1-19. 
Choi-Koh, S. S. (2000). The activities based on van Hiele model using computer as a tool. Journal of the Korea Society of Mathematical Education Series D: Research in Mathematical Education, 4(2), 63-77.

Erdoğan, T., \& Durmuş, S. (2009). The effect of the instruction based on Van Hiele model on the geometrical thinking levels of preservice elementary school teachers. Procedia-Social and Behavioral Sciences, 1(1), 154-159. doi.org/10.1016/j.sbspro.2009.01.029.

Fraser, B. J., \& Kahle, J. B. (2007). Classroom, home and peer environment influences on student outcomes in science and mathematics: An analysis of systemic reform data. International Journal of Science Education, 29(15), 1891-1909.

Fuys, D., Geddes, D., \& Tischler, R. (1988). The van Hiele model of thinking in geometry among adolescents. Journal for Research in Mathematics Education. Monograph, 3, i-196.

Geddes, D., \& Fortunato, I. (1993). Geometry: Research and classroom activities. Research Ideas for the Classroom: Middle grades mathematics, 199-222.

Georgiou, S. N., Stavrinides, P., \& Kalavana, T. (2007). Is Victor better than Victoria at maths? Educational Psychology in Practice, 23(4), 329-342.

Gorozidis, G., \& Papaioannou, A. G. (2014). Teachers' motivation to participate in training and to implement innovations. Teaching and Teacher Education, 39, 1-11.

Hassan, A. A. (2015). Effect of Van Hiele's Geometric Model on Pedagogical Abilities of Nigeria Certificate in Education Mathematics Students in Niger state. Unpublished Ph.D thesis, Ahmadu Bello University Zaria, Nigeria.

Hoffer, A. (1983). Van Hiele-based research. In R. Lesh \& M. Landau (Eds.) Acquisition of mathematics concepts and processes (pp. 205-227). New York: Academic Press

Karjanto, N. (2017). Attitude toward mathematics among the students at Nazarbayev University Foundation Year Programme. International Journal of Mathematical Education in Science and Technology, 48(6), 849-863.

Krippendorff, K. (2018). Content analysis: An introduction to its methodology. Sage publications.

Lipnevich, A. A., MacCann, C., Krumm, S., Burrus, J., \& Roberts, R. D. (2011). Mathematics attitudes and mathematics outcomes of US and Belarusian middle school students. Journal of Educational Psychology, 103(1), 105.

Ma, X. and Kishor, N. (1997). Assessing the relationship between attitude toward mathematics and achievement in mathematics: a meta-analysis. Journal for Research in Mathematics Education, 28(1), 26-47.

Mata, M. D. L., Monteiro, V., \& Peixoto, F. (2012). Attitudes towards mathematics: Effects of individual, motivational, and social support factors. Child development research, 2012. ID 876028, http://dx.doi.org/10.1155/2012/876028

Mato, M. and De la Torre E.(2010). Evaluación de las actitudes hacia las matemáticas y el rendimiento academic. $P N A, 5(1), 197-208$,

Mayberry, D. (1983). "Teacher-Student Interaction in Urban At-Risk Classrooms: Differential Behavior, Relationship Quality, and Student Satisfaction with School." The Elementary School Journal, 100, 57-70. 
Effects of van Hiele's phase-based teaching strategy and gender on pre-service mathematics teachers' attitude towards geometry in Niger State, Nigeria

H. Usman, W. T. Yew, and S. Saleh

Mogari, D. (1999). Attitude and Achievement in Euclidean Geometry.[Online]: Retrieved from URL: http://math. unipa. it/ grim/EMogari9.

Nkwe, D. T. (1985). Teachers attitude, with special references to mathematics teaching. Unpublished MEd Dissertation, University of Witwatersrand, Johannesburg, South Africa.

Obi, C. N., Agwagah, U. N. V., \& Agah, J. J. (2014). Effect of Origami on Students' Retention in Geometry. IOSR Journal of Research \& Method in Education (IOSR-JRME), 4(5), 4650 .

Pallant, J. (2010). SPSS survival manual: A step by step guide to data analysis using SPSS . Maidenhead.

Petty, R. E. (2018). Attitudes and persuasion: Classic and contemporary approaches. Routledge.

Sanchez, K. Zimmerman, 1., \& Ye, r.(2004). Secondary students' attitudes toward mathematics. Academic Exchange Quarterly, 8(2), 56-60.

Savelsbergh, E. R., Prins, G. T., Rietbergen, C., Fechner, S., Vaessen, B. E., Draijer, J. M., \& Bakker, A. (2016). Effects of innovative science and mathematics teaching on student attitudes and achievement: A meta-analytic study. Educational Research Review, 19, $158-172$.

Slavik, P. M. (2015). Students' attitudes toward mathematics in a spreadsheet-based learning environment. Kent State University.

Sonnert, G., Sadler, P. M., Sadler, S. M., \& Bressoud, D. M. (2015). The impact of instructor pedagogy on college calculus students' attitude toward mathematics. International Journal of Mathematical Education in Science and Technology, 46(3), 370-387.

Steiner, D., \& Mendelovitch, M. (2017). I'm The Same Teacher": The attitudes of science and computer literacy teachers regarding integrating ICT in instruction to advance meaningful learning. EURASIA Journal of Mathematics, Science and Technology Education, 13(5), 1259-1282.

Sun, Z., Xie, K., \& Anderman, L. H. (2018). The role of self-regulated learning in students' success in flipped undergraduate math courses. The Internet and Higher Education, 36, 41-53.

Sunzuma, G., Masocha, M., \& Zezekwa, N. (2013). Secondary school students' attitudes towards their learning of geometry: a survey of Bindura urban secondary schools.

Surya, E., \& Syahputra, E. (2017). Improving High-Level Thinking Skills by Development of Learning PBL Approach on the Learning Mathematics for Senior High School Students. International Education Studies, 10(8), 12-20.

Tapia, M., Marsh, G.E. (2004). "An instrument to measure mathematics attitude" Academic exchange quarterly 8(2) 16-22

Thompson, K. M. (1993). Geometry Students'Attitudes toward Mathematics: An Empirical Investigation of Two Specific Curricular Approaches. Unpublished Master's Thesis, California State University Dominguez Hills, USA. 
Turner, P. E., Johnston, E., Kebritchi, M., Evans, S., \& Heflich, D. A. (2018). Influence of online computer games on the academic achievement of nontraditional undergraduate students. Cogent Education, 5(1), 1437671.

Usiskin, Z. (1982). van Hiele levels and achievement in secondary school geometry. (Final Report of the Cognitive Development and Achievement in Secondary School Geometry Project) Chicago: University of Chicago (ERIC Document Reproduction Service Number ED220288).

Wells, C. S., \& Wollack, J. A. (2003). An instructor's guide to understanding test reliability. Testing \& Evaluation Services. University of Wisconsin. 